\section{Designing a BDI Agent Reactant Model of BehaVIOURAL ChANGE INTERVENTION}

\author{
Ojeniyi Adegoke*, Azizi Ab Aziz, Yuhanis Yusof
}

Human-Centred Computing Group (HCC), Computational Intelligence Platform (CIP), School of Computing (SOC), College of Arts and Sciences (CAS), Universiti Utara Malaysia, 06010 UUM Sintok, Kedah, Malaysia
Article history

Received

15 June 2015

Received in revised form

1 October 2015

Accepted

13 October 2015

*Corresponding author adegoke@ahsgs.uum.my

\section{Graphical abstract}

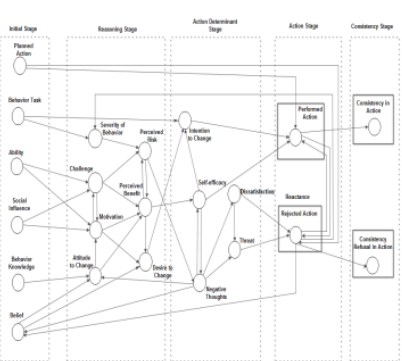

\begin{abstract}
Belief-Desire-Intention (BDI) model is well suited for describing agent's mental state. The BDI of an agent represents its motivational stance and are the main determinant of agent's actions. Therefore, explicit understanding of the representation and modelling of such motivational stance plays a central role in designing BDI agent with successful behavioural change interventions. Nevertheless, existing BDI agent models do not represent agent's behavioural factors explicitly. This leads to a gap between design and implementation where psychological reactance has being identified as the cause of BDI agent behavioural change interventions failure. Hence, this paper presents a generic representation of BDI agent model based on behavioural change and psychological theories. Also, using mathematical analysis the model was evaluated. The objective of the proposed BDI agent model is to bridge the gap between agent design and implementation for successful agent-based interventions. The model will be realized in an agentbased application that motivates children towards oral hygiene. The study explicitly depicts how agent's behavioural factors interact to enhance behaviour change which will assist agent-based intervention designers to be able to design intervention that will be void of reactance.
\end{abstract}

Keywords: Belief-Desire-Intention, BDI model, behaviour change, behavioural change intervention, psychological reactance

\begin{abstract}
Abstrak
Model Kepercayaan-Keinginan-Niat (BDI) adalah sesuai untuk menggambarkan keadaan mental sesuatu Agen. Agen BDI mewakili pendirian motivasi dan menentukan tindakan utama sesuatu agen. Oleh itu, pemahaman yang jelas daripada perwakilan dan pemodelan agen dapat menetapkan sesuatu pendirian motivasi dan memainkan peranan utama dalam agen BDI bagi mencapai kejayaan dalam campur tangan perubahan tingkah laku. Walau bagaimanapun, model agen BDI yang wujud kini masih lagi tidak dapat mewakili faktor tingkah laku agen dengan jelas. Ini membawa kepada jurang antara reka bentuk dan pelaksanaan yang berkaitan dengan model sedia ada, di mana regangan psikologi telah dikenal pasti sebagai penyebab penghadan agen BDI dalam kegagalan campur tangan perubahan kelakuan. Oleh itu, kertas kerja ini membentangkan perwakilan generik model agen BDI yang berdasarkan perubahan tingkah laku dan teori psikologi. Objektif model agen BDI yang dicadangkan adalah untuk merapatkan jurang antara rekabentuk ejen dan pelaksanaan dalam campur tangan agen dengan berjaya. Model ini akan dinilai dengan membangunkan aplikasi berasaskan agen yang akan dilaksanakan untuk memujuk kanak-kanak ke arah kebersihan mulut.
\end{abstract}

Kata kunci: Kepercayaan-Keinginan-Niat, Model BDI, perubahan tingkah laku, perubahan campur tangan tingkah laku, regangan psikologi 


\subsection{INTRODUCTION}

Research in Belief Desire Intention (BDI) agents that are capable of rational behaviour has received a great deal of attention from multi-agent research community in recent years. This is due to many reasons, but perhaps the most compelling is the fact that BDI model comprises of philosophical model of human practical interaction and reasoning. Although some studies have explored BDI agent model for examples in [1], [2], [3], [4], [5], [6] and [7]. In the study by [1], a planning theory of intention was proposed where agent intentions are treated as elements of partial plans of action. The plans play basic roles in practical reasoning; roles that support agent decision activities over time and social communication.

However, none of these studies explicitly depicts agent mental state in behavioural change intervention activities. Also, these BDI models do not explicitly describe mechanisms for the agent factors to interact between each other in order to achieve behaviour change. Therefore, this article presents a $\mathrm{BDI}$ agent model of behaviour change that analyse agent's factors and deflect psychological reactance in agent-based application intervention. This article is structured as follows. After an introduction of the area of $\mathrm{BDI}$ and its underlying concepts, first the dynamical model for reactant in behaviour change by means of simulation. Next, the main concepts of this model are specified, and results from simulation experiments are discussed and verified. Finally, a discussion concludes this article.

\subsection{THE UNDERLYING CONCEPTS OF BDI AGENT MODEL}

The BDI model is closely associated with intelligent agents. However the BDI agent does not possess some characteristics associated with intelligent agents. For example, it allows agents to have private beliefs, but does not force them to be private and not only to cover agent communication [8], [9]. Consequently, the BDI software model is an attempt to solve a problem that has more to do with plans and planning (the choice and execution thereof) than it has to do with the explicit understanding of mechanism that leads to agent action and plans. Thus, in behaviour change intervention, BDI agent focus more on agent plans and planning factors in achieving their target interventions. Figure 1 depicts the overall functioning of the BDI model

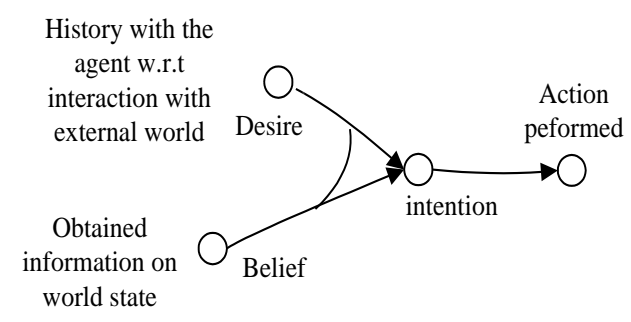

Figure 1 The BDI Structure

In order to explicitly understand how agent can achieve successful behaviour change intervention, explorations were made on psychological theories of behaviour change and psychological reactance. Thus, BDI model is an integrated model based on the following psychological theories and models namely Relapse Prevention Model (RPM), Trans-Theoretical Model (TM), Self-Efficacy Theory (SET), Self-Regulation Theory (SRT), Theory of Reasoned Action (TRA), Theory of Planned Behaviour (TPB) and Health Belief Model (HBM). These existing psychological theories and models were divided into two main groups namely: Social Cognition Models and Stage Models [10].

\subsection{Social Cognition Models (SCMs)}

Social Cognition Models are set of similar theories which show the imperative of cognition and their inter-relationship in the regulation of behaviour [11]. These theories (Self-Efficacy Theory, Self-Regulation Theory, Theory of Reasoned Action and Planned Behaviour and Health Belief Model) that made up the Social Cognition Model only explicate major factors that affect behaviour change [10]. SCMs are used to identify and explain how expectations, judgments, beliefs, and intentions lead to the performance of various behaviours [12].

Despite the widespread use in behaviour change interventions, the SCMs have been criticized by many researchers. For instance, in study [13] criticized the models to have omitted some major factors in behaviour changes. Furthermore, in [14] has pointed out there is an overlap of factors between the different theories.

\subsubsection{Self-Efficacy Theory (SET)}

Self-Efficacy is the appraisal of one's self ability and capability to complete tasks and reach pre-defined objectives and goals. Individual's knowledge acquisition might be directly related to observations of others within the context of social interactions and experiences. There are three main events related to the self-efficacy traits, namely; 1) one's ability to control the resultant behaviour, 2) perceived control over external barrier, and 3) having confident in one's own ability to perform the actions that might lead to the change [15].

This implies that for behavioural change to occur there is need for a strong inter-self-motivation (self- 
efficacy) to perform the action that might lead to the change. In many cases, this motivation is built as a result of social interaction with others [16]. In addition, it also can be argued that some of the behaviours can be resulted from the emotional responses determined largely by personality, behavioural nature and social factors, which are controlled heavily by evolution, and has little to do with motivation or observation [17]. For instance, jealousy can drive one to behave in a way that is not consistent with one's normal behaviour and some personality, social and behavioural nature factors were not considered in this theory.

\subsubsection{Self-Regulation Theory (SRT)}

Self-regulation theory suggests that for an intervention to result to behaviour change, the user should experience some level of decline in the effect of self-determination, self-discipline and self-control [18]. It explains that we expend effort in control of what we think, say, do and trying to be the person we want to be, both in particular situations and in the longer-term [19].

Therefore, self-regulation is a mechanism to prevent us from doing things we know we should not do. For instance, caution on saying impolitely words to other people. Self-regulation can be applied in creating positive behaviours, such as studying for exams. The theory is individualistic based and does not consider social norms and environmental factors. However it explores more of inner motivation or ability that leads to behaviour change than external motivation. While in the real world, it takes both inter and external factors to lead to behaviour change [20].

\subsubsection{The Theory of Reasoned Action and the Theory of Planned Behaviour (TRA \& TPB)}

The Theory of Reasoned Action (TRA) is used to initialize conditions under which attitude as a precursor to predict behaviour [21]. The primary components of TRA are; behavioural intention, attitude, and subjective norm. TRA suggests that a person's behavioural intention depends on the person's attitude about the behaviour, and subjective norms. This brought in context that a person's volitional (voluntary) behaviour is predicted by his or her attitude towards that behaviour and how he or she thinks other people would view them if they performed the behaviour [22].

A person's attitude, combined with subjective norms, forms this behavioural intention. If they intend they will do it [23]. Behavioural intention measures a person's relative strength of intention to perform the behaviour. Attitude consists of beliefs about the consequences of performing the behaviour multiplied by his or her evaluation of these consequences. Subjective norm is seen as a combination of perceived expectations from relevant individuals or groups along with intentions to comply with these expectations [24].

This theory depicts that environmental, demographical factors do not directly influence the likelihood of a person performing behaviour; these were regarded as peripheral factors yet it has been observed that these peripheral aspects are very significant factor as to whether behaviour change shall occur. But this was later improved on by the theory of planned behaviour; which gives a better and refined understanding about attitude and behaviour.

Theory of Planned Behaviour was designed out of a counter-argument against the high relationship between behavioural intention and actual behaviour, as the results of some studies shown that behavioural intention does not always lead to actual behaviour because of circumstantial limitations [25]. Since behavioural intention cannot be the exclusive determinant of behaviour where an individual's control over the behaviour is incomplete [26]; Ajzen introduced the Theory of Planned Behaviour by adding a new factor known as perceived behavioural control [27].

By this, he extended the theory of reasoned action to cover non-volitional behaviours for predicting behavioural intention and actual behaviour. This concept has been widely use in persuasion and behavioural prediction in many domains like marketing, media, communication, computer science and other. However, the theory of planned behaviour overlooks emotional variables such as threat, fear, mood and negative or positive feeling and assessed them in a limited fashion.

\subsubsection{The Health Belief Model (HBM)}

The Health belief model consist of perceived susceptibility, perceived severity, perceived benefits, perceived barriers, perceived motivation and perceived cue as shown [10]. Perceived susceptibility means vulnerability of the audience's perceived risk of performing the behaviour. Perceived severity connotes the seriousness of the action and its consequences as perceived by the audience.

In contrast to perceived risk, the perceived benefits refer to the perceived advantages of the alternative course of action including the extent to which it reduces the risk of the behaviour or the severity of its consequences. Perceived barriers (or perceived costs) refer to the perceived disadvantages of adopting the recommended behaviour as well as perceived obstacles that may prevent or hinder successful performance of the behaviour. Perceived motivation is the enabling ability to perform the behaviour while Perceived Cue is a trigger factor that enables the other five concepts to result into behaviour change. Although this model provides a framework to explain and predict behaviour change of individuals, it does not incorporate social influence, personality and environment factors [28]. 


\subsubsection{Fogg Behaviour Model (FBM)}

The model was proposed by study [29] and it illustrates three factors essential for behaviour change to occur. These factors are: 1) motivation, 2) ability, and 3) triggers. For the target behaviour to occur, a person must have sufficient motivation, enabling ability, and an effective trigger. All three factors must be present at the same instant for the behaviour to occur.

The model had been used in many motivational and persuasive system designs. For instance, in study [30], the researchers incorporated the Fogg behaviour model to design a micro-blogging site called Twitter Me. The site was integrated with phone applications via social media, aims to motivate teenage girls towards exercises.. In another study[31] implemented the Fogg behaviour model to design a social tagging system application known as Tagliatelle, to support healthier eating habits for weight reduction programmes.

\subsection{Stage Models}

These are set of theories that are based on segmentation approach of behavioural change factors. It defined movement of factors through a pattern of distinct stages over time and these stages can be explained only based on their distinguishing characteristics [32]. In particular, stage models in cognitive development have layers of succession which are grouped into two distinct stages namely output and initial stages. The output stage (later stages) integrates the achievements of initial stage (earlier stages). And each has well defined mental processes which are meant for them which might be dependent on time frame

\subsubsection{The Relapse Prevention Model (RPM)}

Relapse is an outcome of behaviour that can be negative in terms of behaviour change processes. An initial setback, or lapse, may either translate into a return to the previous problematic behaviour, known as relapse, or into the individual turning again towards positive change, called prolapsed depending on the situation [33]. Study [34] argued that relapse is multi-determined, especially by selfefficacy, outcome expectancies, craving, motivation, coping, emotional states, and interpersonal factors. In particular, high self-efficacy, negative outcome expectancies, potent availability of coping skills following persuasion, positive effect, and functional social support are expected to predict positive outcome.

This theory is classified as stage model because of it stage-wise structural explanation of behaviour change factors. Although the model is widely used in drug related health behaviour change interventions but the primary limiting factor is that in humans, relapse rarely follows the strict extinction of drugseeking behaviour. It is mainly based on drug-related case which cannot be generalized. Additionally, human self-reports show that drug-associated stimuli play a lesser role in craving in humans than in the laboratory models [35].

\subsubsection{The Trans-Theoretical Model (TM)}

The theory of Trans-Theoretical Model is one of the successful ones that have been applied to many behaviour changes interventions. It involves transitions between the stages of behaviour change as affected by a set of factors known as the processes of change. These include decisional balance (the pros and cons of change), self-efficacy (confidence in the ability to change across problem situations), and situational temptations to engage in the problem behaviour, and behaviours which are specific to the problem area [36]. Study [37] summarized the model into five stage of behaviour change name; pre- contemplation, contemplation, preparation, action, and maintenance.

In addition, study done by [38] suggested that progress on these stages depend on awareness, motivation and commitment of the audience. Precontemplation is the stage where the audience is unaware of the need to change the behaviour (not aware of the benefits of changing his behaviour). Contemplation is the stage that the audience has gain awareness about the benefits or gains due if the behaviour is change. Preparation is the stage of building internal motivation and strength to perform the behaviour. Action stage is when behaviour change had occurred but the audience is building commitment to preserve the change. The maintenance stage is where there is aware of possible slip back or relapses to pervious stage or formal behaviour. This model is very imperative to understand how users can develop long lasting behaviour change during intervention programme. However, study [39] criticized the model that the assumption on individuals typically making coherent and stable plans is not true. Human are known for incoherent and unstable decision and plans.

\subsection{The BDI Model Concept}

The above theories and models described different factors involved in behaviour change process however; there were overlapping descriptions of these factors. It could be seen that many of these theories and models used similar factor names whereas different concepts were being defined. Hence, the proposed BDI agent model was based on integration of these psychological theories and models of behaviour change as presented in Table 1. 
Table 1 Concepts in BDI Agent Model

\begin{tabular}{|c|c|c|c|c|}
\hline No & Concept & Formalization & Description & Related Theory \\
\hline 1 & Ability & $A b$ & The capability to perform a behaviour & FBM, SET \\
\hline 2 & $\begin{array}{l}\text { Behaviour } \\
\text { Knowledge }\end{array}$ & $B k$ & The knowledge about the behaviour & TM, FBM \\
\hline 4 & Social Influence & $\mathrm{Si}$ & External factors that enable the behaviour & TPB, TRA \\
\hline 5 & Attitude to Change & AC & Mental state & TPB, TRA \\
\hline 6 & Challenge & $\mathrm{Cg}$ & Perceived obstacle or impediment & HBM, TPB \\
\hline 9 & Perceived Benefit & $\mathrm{Pb}$ & Positive consequences of the behaviour & HBM, TPB \\
\hline 10 & Threat & $\mathrm{Hr}$ & Perceived risk to perform behaviour & FBM, HBM \\
\hline 11 & Intention to Change & IC & The Willingness to perform the behaviour & FBM, HBM, RPM \\
\hline 12 & Dissatisfaction & Df & Negative reaction toward the behaviour & $\mathrm{HBM}, \mathrm{TPB}$ \\
\hline 13 & Negative Thoughts & $\mathrm{Ng}$ & Negative perception and belief about the behaviour & HBM, TPB \\
\hline 14 & Self-efficacy & $\mathrm{Se}$ & $\begin{array}{l}\text { The belief in one's capabilities or ability to perform a target } \\
\text { behaviour or action. }\end{array}$ & RPM, TPB, SET \\
\hline 18 & Belief & $\mathrm{Bf}$ & $\begin{array}{l}\text { A psychological state in which an individual holds a } \\
\text { conjecture or premise on the validity and truthfulness of a } \\
\text { behaviour or action }\end{array}$ & TPB, HBM, TRA \\
\hline 19 & Desire to Change & DC & Emotional sense of longing or wishing to change & SRT \\
\hline 20 & $\begin{array}{l}\text { Consistency in } \\
\text { Action }\end{array}$ & $\mathrm{Ca}$ & $\begin{array}{l}\text { A state when the action or behaviour is obtainable } \\
\text { continuously }\end{array}$ & RMP, TM \\
\hline 21 & Action Reject & $\mathrm{Ar}$ & A state when the behaviour or action is deflected & SET \\
\hline 22 & $\begin{array}{l}\text { Consistency Refusal } \\
\text { in Action }\end{array}$ & $\mathrm{Cr}$ & $\begin{array}{l}\text { A state when the behaviour or action is deflected } \\
\text { continuously }\end{array}$ & SET \\
\hline
\end{tabular}

Table 1 explicitly presented relevant factors and model concept that were used in formalization of the $\mathrm{BDI}$ model while Figure 1 depicts the interaction of the identified agent's factors that produce behaviour change.

The agent's belief is represented under the initial stage where information about the agent's plan is conceived. This stage can also be a term information state where agent acquires knowledge and belief on its action. On the other hand, agent's desire is represented in the reasoning stage where it is influenced by many other interplaying factors such as severity of the action, perceived benefit of the action to the agent and the nature of challenge the action is posing to agent's plan and agent's desire which form the reasoning stage of the agent.

The action determinant stage house the agent intention and it is known as the deliberative state of an agent. This is the stage that depicts the action that an agent has chosen to perform. Intentions are desires to which the agent is somewhat committed to and this commitment is represented in the agent's self-efficacy.

\subsection{FORMALIZATION AND SIMULATION}

The arrows in Figure 2 denote causal dependencies of interplaying factors. The formalization of the model is based on [40] with respect to time (t). Derived from on the concept of the model severity of behaviour (Sb) is the strictness of the consequences of behaviour. The designed model conceptualized the idea that it is high when both behaviour task (Ba) and action reject (Ar) are high which was formalized as shows in equation (1).

Sb $(t)=B a(t)[1-(1-A r(t))]$

Se $(t)=P b(t) \cdot[1-N g(t)]$ 


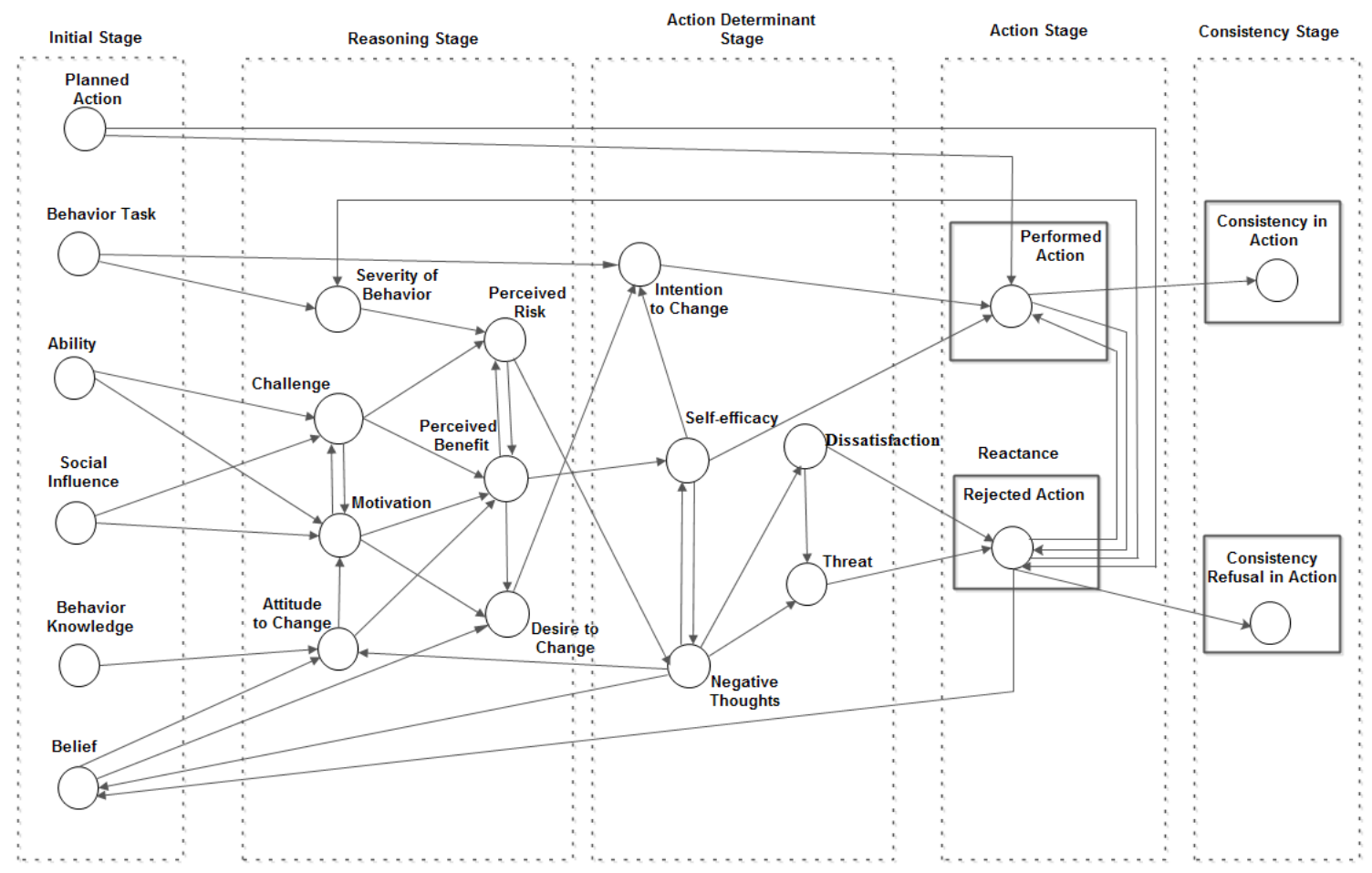

Figure 2 The BDI Model of Reactant

Challenge $(\mathrm{Cg})$ is perceived obstacle or impediment to target behaviour. From the designed model challenge is high when any two of ability (Ab), social influence (Si) and motivation (Mv) are high which was formalized as shown in equation (3). This same procedure was used for the concept formalization of both perceived benefit $(P b)$ and performed action $(P C)$ as presented in equations (4) and (5) respectively.

$C g(t)=\mathrm{w}_{\mathrm{c} 1} \cdot A b(t)+\mathrm{w}_{\mathrm{c} 2} \cdot S i(t)+\mathrm{w}_{\mathrm{c} 3} \cdot M v(t)$

$P b(t)=\left[\mathrm{w}_{\mathrm{pb}} \cdot A c(t)+\mathrm{w} \mathrm{pb} 2 \cdot M v(t)+\mathrm{w}_{\mathrm{pb} 3} \cdot C g(t)\right] \cdot(1-\operatorname{Pr}(t))$

$P c(t)=\left[\mathrm{wPc}_{\mathrm{Pc}} \cdot P a(t)+\mathrm{wPc}_{\mathrm{P} 2} . I c(t)+\mathrm{wPc}_{\mathrm{P} 3} \cdot S e(t)\right] \cdot(1-A r(t))$

$A r(t)=\left[\mathrm{w}_{\mathrm{Ar} 1} \cdot D f(t)+\mathrm{w}_{\mathrm{Ar} 2} \cdot H r(t)+\mathrm{w}_{\mathrm{Ar} 3} \cdot \operatorname{Pa}(t)\right] \cdot(1-(P c(t))$

where $\quad \sum_{j=3}^{1} W c j=1, \quad \sum_{j=3}^{1} W p b j \quad=1, \quad \sum_{j=3}^{1} \mathrm{Wpcj}=1$, $\sum_{j=3}^{1} W m j$ and $\sum_{j=3}^{1}$ Warj $=1$

$w_{c 1}, w_{c 2}, w_{c 3}, w_{p b 1}, w_{p b 2}, w_{p b 3}, w_{P c l}, w_{P c 2}, w_{P c 3}, w_{A r 1}, w_{A r 2}, w_{A r 3} w_{m 1}$ $w_{m 2}$ and $w_{m 3}$ are the weights factors for the respective equations.

Similarly, motivation is the simulative drive and intrinsic interest in performing behaviour. Based on the designed model motivation is low if attitude to change (AC) is low and one of ability, challenge and social influence (Si) are low as presented in equation (6). The attitude to Change (Ac) is the mental state which implies a formed view or perception about a behaviour. It is high when negative thoughts $(\mathrm{Ng})$ is low and any of behaviour knowledge $(B k)$ or belief $(B f)$ is high as presented in equation (7). This same procedure was used for the concept formalization of equations (8), (9), (10), (11), (12) and (13).

$M v(t)=\sigma\left(\mathrm{w}_{\mathrm{m} 1} A b(t)+\mathrm{w}_{\mathrm{m} 2} \cdot S i(t)+\mathrm{w}_{\mathrm{m} 3} \cdot C g(t)\right)+(1-\sigma)(A c(t))$

$A c(t)=[\gamma \cdot B k(t)+(1-\gamma) \cdot B f(t)][1-N g(t)]$

$\operatorname{Pr}(t)=S b(t) \cdot[1-\rho \cdot C g(t)+(1-\rho) \cdot P b(t))]$

$D c(t)=B f(t) \cdot[\eta \cdot M v(t)+(1-\eta) \cdot P b(t)]$

$I c(\mathrm{t})=D c(\mathrm{t}) \cdot[v \cdot S e(t)+(1-v) \cdot B a(t)]$

$N g(\mathrm{t})=\psi \cdot \operatorname{Pr}(t)+[(1-\psi) \cdot \operatorname{Se}(t)]$

$H r(\mathrm{t})=\phi . D f(t)+[(1-\phi) \cdot N g(t)]$

Likewise, based on the designed model dissatisfaction (Df) is the negative unpleasant feeling, negative expectation and negative reaction from behaviour. Dissatisfaction (Df) is high when negative thought $(\mathrm{Ng})$ is high which was formalized in equation (6). The same procedure were used to formalized for consistency in action ( $\mathrm{Ca}$ ) and consistency refusal in action (Cr) as presented in equations (7) and (8). Also, these equations (14) to (15) are known as the temporal equation of the model because they show the resultant outcome of behaviour. While equations (1) to (13) are the instantaneous equations because they give resultant process that led to the temporal equations. 
$D f(t+\Delta \mathrm{t})=D f(t)+\lambda . .[N g(t)-D f(t)] ..(1-D f(t)) ..(D f(t.) . \Delta t)$

$C a(t+\Delta \mathrm{t})=C a(t)+\zeta . .[P c(t)-C a(t).] .(1-C a(t).) \cdot(C a(t.) \cdot \Delta t)$

$C r(t+\Delta t)=C r(t)+\varphi . .[A r(t)-C r(t)] ..(1-C r(t)) ..(C r(t.) . \Delta t)$

Whereas: $\lambda, \zeta$ and $\varphi$ are the regulating parameters, and $\Delta t$ refers to the change rate in time $(t)$

Based on the formal model, the instantaneous formalization parameters represent the equalization of corresponded contribution towards the overall equations. In addition, parameters for temporal equations denote the contribution for change rate. The formal model was implemented in the numerical programming language (Matlab) using four case conditions as shown in Table 2. In addition, the weights (w) were assigned 0.33 respectively, while all regulating parameters were assigned 0.5 based on suggestions made by [41] and [42].

Table 2 Simulation Case Condition

\begin{tabular}{|l|l|l|l|l|}
\hline & \multicolumn{4}{|c|}{ Case Condition } \\
\hline Concept & Uninspiring & $\begin{array}{l}\text { Belief } \\
\text { Deficient }\end{array}$ & $\begin{array}{l}\text { Ability } \\
\text { Deficient }\end{array}$ & Influential \\
\hline $\mathrm{Pa}$ & 0.2 & 0.2 & 0.2 & 0.5 \\
\hline $\mathrm{Ba}$ & 0.9 & 0.9 & 0.9 & 0.2 \\
\hline $\mathrm{Ab}$ & 0.2 & 0.9 & 0.2 & 0.9 \\
\hline $\mathrm{Si}$ & 0.2 & 0.9 & 0.2 & 0.9 \\
\hline $\mathrm{Bk}$ & 0.2 & 0.2 & 0.9 & 0.9 \\
\hline $\mathrm{Bf}$ & 0.2 & 0.2 & 0.9 & 0.9 \\
\hline
\end{tabular}

Each of the four case conditions defines different characteristics that can be possessed by an agent. For instance, uninspiring defines an agent with high Behavioural task (Ba) and low Planned action (Pa), Ability (Ab), Society influence (Si), Behavioural knowledge (Bk) and Belief (Bf). While ability deficient defines an agent with high Behavioural Tasks (Ba), Behavioural knowledge (Bk), and Belief (Bf) but low in
Planned action (Pa), Ability ( $A b)$ and Society Influence (Si). Figures 2, 34 and 5 illustrate the case condition simulation results. The simulation results show the fundamental uniqueness of each case condition. The established simulations reflected that the model can account for related behavioural phenomenon.

\subsection{RESULTS}

Based on Figure 3 it can be observed that dissatisfaction leads both consistency refusal in action and consistency in action. Dissatisfaction was found to strike up to the maximum level, whereas consistency in action is declining towards baseline level. This implies that when an agent is experiencing this condition, then its action will be characterized as "extremely high dissatisfaction" and "extremely low consistency in action" which indicates that the agent will experience difficulty to perform the target behaviour. This later leads to extreme susceptible towards high dissatisfaction.

Figure 4 depicts a result that was almost similar to the uninspiring case condition attribution as shown in Figure 3. However, the range boundaries between cases were not as significant compared to cases as depicted in Figure 3. However, the dissatisfaction level was found to influence both consistency refusal in action and consistency in action. The margin between dissatisfaction and consistency refusal in action levels is wider than the margin between consistency refusal in action and consistency in action. This implies that when an agent acquires this case condition attribution then its action will be characterized by a high dissatisfaction and low consistency in action which indicates that the agent will not be able to consistently perform the target behaviour. The level of the agent's dissatisfaction with the target behaviour is lower compared to the first case of condition attribution in Figure 3.

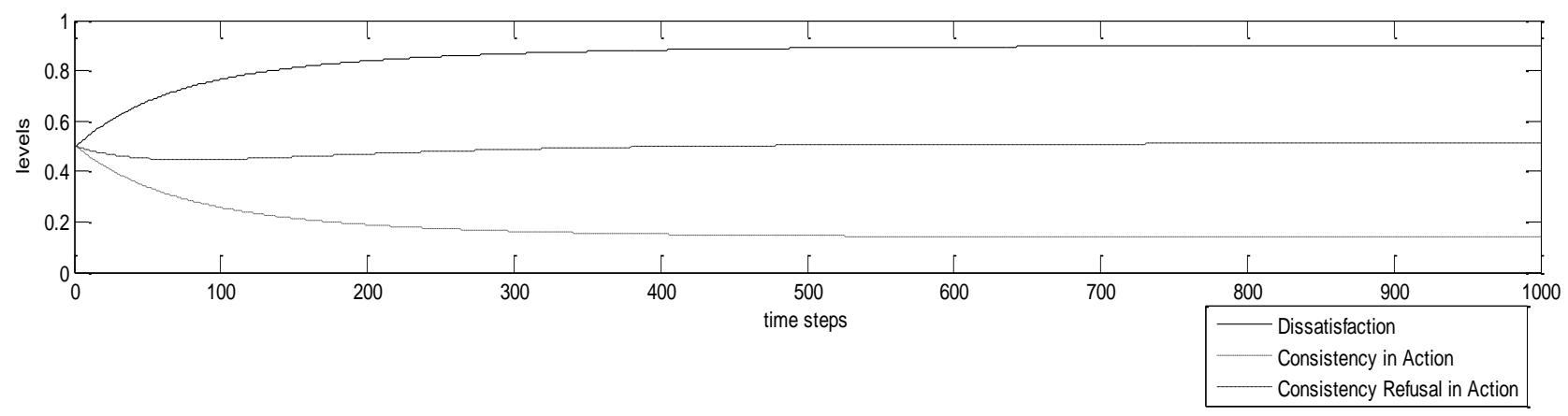

Figure 3 Simulation of Uninspiring Case Condition 


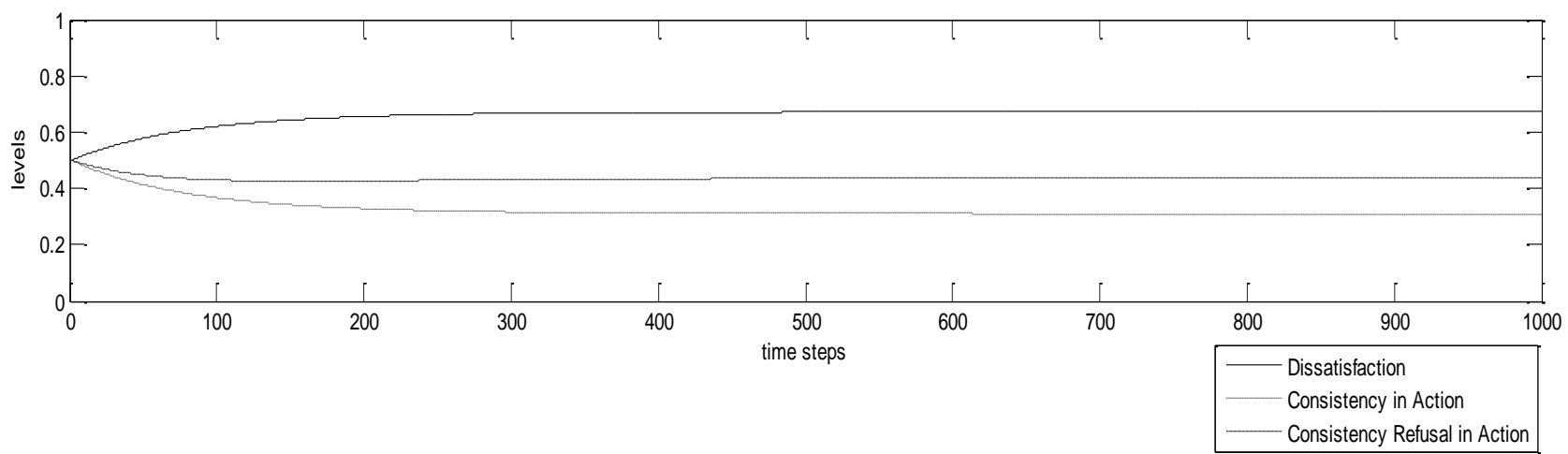

Figure 4Simulation of Belief Deficient Case Condition

From Figure 5, it can be seen that dissatisfaction leads both consistency in action and consistency refusal. Nevertheless, by comparing this result compared to other previous case conditions (as shown in Figure 3 and 4 ) the level of consistency in action was found to influence the consistency refusal in action. Furthermore, the consistency refusal in action level is monotonically close to 0 , the while consistency in action was remain constant at 0.5 . This is related that when an agent acquires this case condition attribution then its action will be characterized by a high dissatisfaction whereas consistency in action performed will be possible at a very low and constant level. The agent will be able to achieve target behaviour. Nevertheless, due to the deficient in both ability and social influence, the agent will be highly dissatisfied with its achieved targets.

Based on simulation traces as shown in Figure 6, it can be depict that consistency in action leads both dissatisfaction and consistency refusal. It is worth it to show that there is a very wide lagging range margin between dissatisfaction and consistency refusal in action and also a close leading range margin between consistency in action and dissatisfaction. This can be explained due to the low attribute of behaviour task. This result is supported by study [29], as it can be pointed out that when behaviour is not challenging then the probability of its being perform consistently will be low. In other words, this implies that when an agent acquires this case condition attribution then its action will be characterized by a high consistency in action, reduced level in dissatisfaction and extremely low consistency refusal in action. The agent will be able to consistently perform the target behaviour while there will be a little level of dissatisfaction due to low behaviour task.

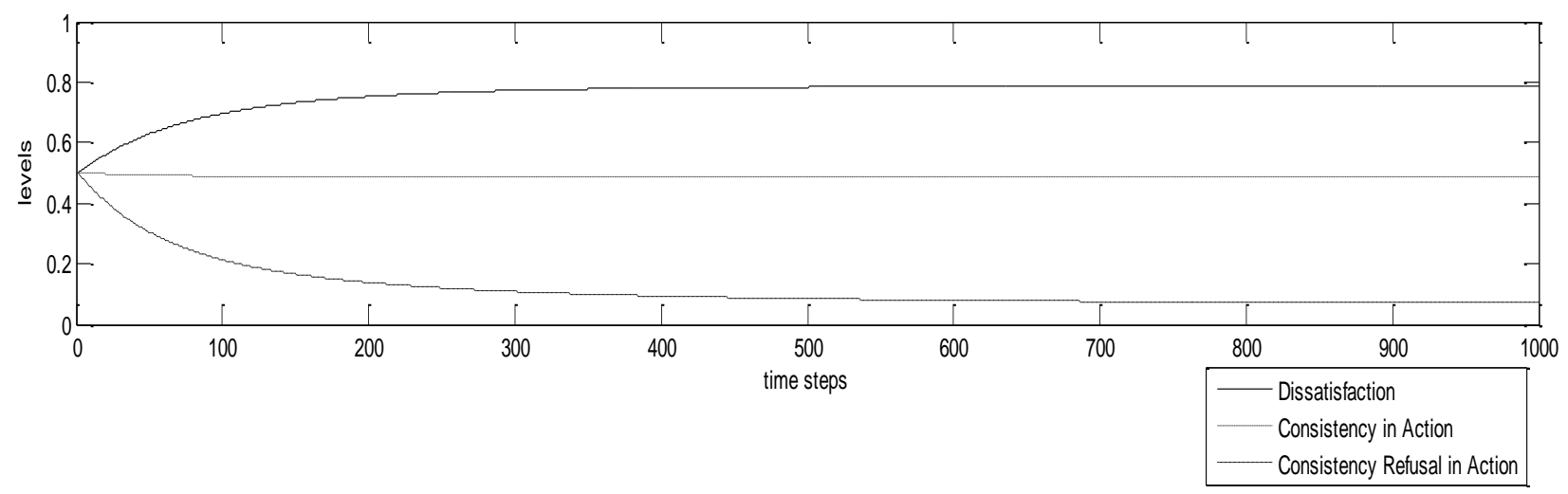

Figure 5 Simulation of Ability Deficient Case Condition 


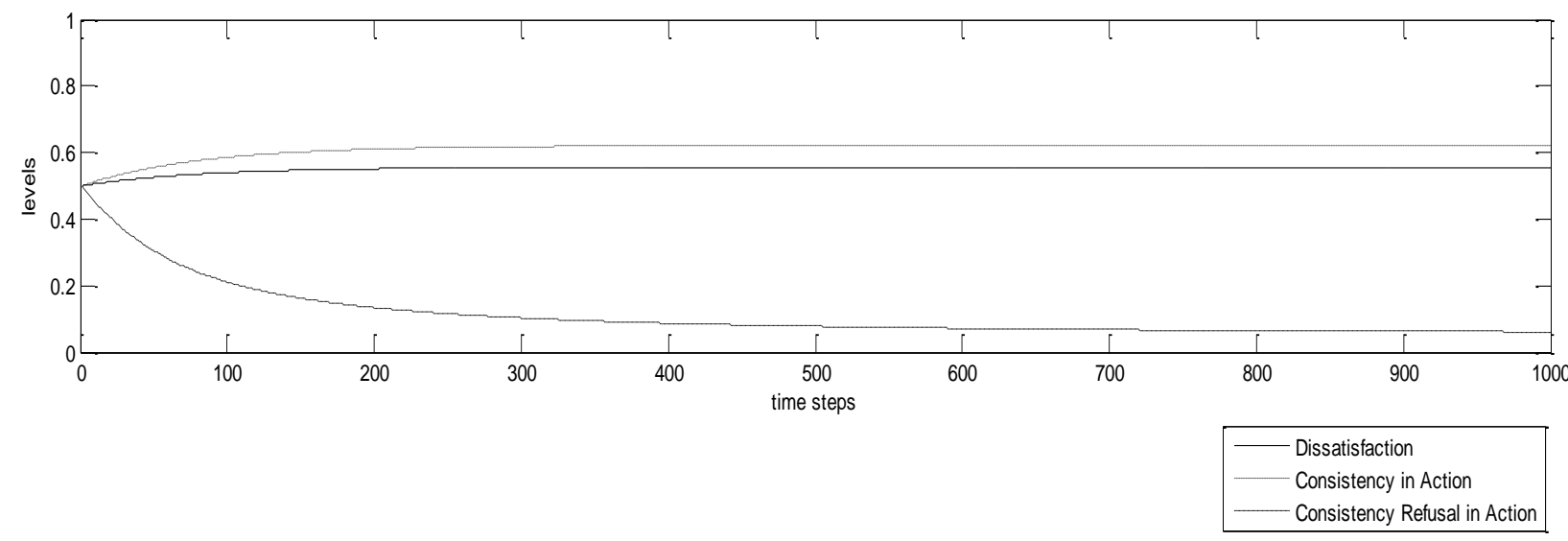

Figure 6 Simulation of Influential Case Condition

\subsection{MATHEMATICAL VERIFICATION}

For the mathematical verification, equillibria analysis is used to describe situations in models where the values (continuous) approach a limit under certain conditions and stabilize. It means, if the dynamics of a model is described by a differential equation, then equilibria can be estimated by setting a derivative (or all derivatives) to zero. One important note that an equillibria condition(s) is considered stable if the model always returns to it after small disturbances. These equillibria conditions are interesting to be explored, as it is possible to explain them using the knowledge from the theory or problem that is modelled. As such, the existence of reasonable equilibria is also an indication for the correctness of the model. To obtain possible equilibrium values for the other variables, first the temporal equations are described in a differential equation form.

$$
\begin{aligned}
\frac{d D f(t)}{d t} & =\lambda \cdot[N g(t)-D f(t)] \cdot(1-D f(t)) \cdot(D f(t)) \\
\frac{d C a(t)}{d t} & =\zeta \cdot[P c(t)-C a(t)] \cdot(1-\operatorname{Ca}(t)) \cdot \operatorname{Ca}(t)) \\
\frac{d C r(t)}{d t} & =\varphi \cdot[\operatorname{Ar}(t)-\operatorname{Cr}(t)] \cdot(1-\operatorname{Cr}(t)) \cdot \operatorname{Cr}(t))
\end{aligned}
$$

Assuming the parameters $\varphi, \zeta, \lambda$, are nonzero, from the equations $X$ to $Y$, the following cases can be distinguish.

$$
\begin{aligned}
& {[N g(t)-D f(t)] \cdot(1-D f(t)) \cdot(D f(t))=[P c(t)-} \\
& C a(t)] \cdot(1-C a(t)) \cdot C a(t))=0 \\
& [A r(t)-\operatorname{Cr}(t)] \cdot(1-\operatorname{Cr}(t)) \cdot \operatorname{Cr}(t))=0
\end{aligned}
$$

Later these cases can be distinguished into

$$
\begin{aligned}
& (N g=D f) \vee(D f=1) \vee(D f=0) \\
& (P c=C a) \vee(C a=1) \vee(C a=0) \\
& (A r=C r) \vee(C r=1) \vee(C r=0)
\end{aligned}
$$

From here, a first of conclusions can be derived where the equilibrium can only occur when the $\mathrm{Ng}=\mathrm{D}_{f}, \mathrm{Df}=\mathrm{l}$, or $D f=0$.
This later provides possible combinations equillibria points to be further analysed. However due to the huge amount of possible combinations, (in this case, $3^{3}=27$ possibilities), it makes hard to come up with a complete classification of equilibria. However, for some typical cases the analysis can be pursued further.

$$
\begin{aligned}
& {[N g(t)-D f(t)] \cdot(1-D f(t)) \cdot(D f(t))=0} \\
& [P c(t)-C a(t)] \cdot(1-C a(t)) \cdot \operatorname{Ca}(t))=0 \\
& [\operatorname{Ar}(t)-\operatorname{Cr}(t)] \cdot(1-\operatorname{Cr}(t)) \cdot \operatorname{Cr}(t))=0
\end{aligned}
$$

Later these cases can be distinguished into

$$
\begin{aligned}
& (N g=D f) \vee(D f=1) \vee(D f=0) \\
& (P c=C a) \vee(C a=1) \vee(C a=0) \\
& (A r=C r) \vee(C r=1) \vee(C r=0)
\end{aligned}
$$

From here, a first of conclusions can be derived where the equilibrium can only occur when the $\mathrm{Ng}=\mathrm{D}_{\mathrm{f}}, \mathrm{Df}=\mathrm{l}$, or $D f=0$.

This later provides possible combinations equillibria points to be further analysed. However due to the huge amount of possible combinations, (in this case, $3^{3}=27$ possibilities), it makes hard to come up with a complete classification of equilibria. However, for some typical cases the analysis can be pursued further.

\section{Case $1(\mathrm{Ng}=\mathrm{Df})$}

$\mathrm{Se}(t)=P b(t) \cdot[1-D f(t)]$

$A c(t)=[\gamma . B k(t)+(1-\gamma) . B f(t)][1-D f(t)]$

$H r(\mathrm{t})=\phi . D f(\mathrm{t})+[(1-\phi) \cdot D f(\mathrm{t})]$

\section{Case $2(P c=C a)$}

$A r(t)=\left[\mathrm{w}_{\mathrm{Ar} 1} \cdot D f(t)+\mathrm{w}_{\mathrm{Ar} 2} \cdot H r(t)+\mathrm{w}_{\mathrm{Ar} 3} \cdot \operatorname{Pa}(t)\right] \cdot(1-(C a(t))$

\section{Case $3(D f=0)$ \\ $\operatorname{Ar}(t)=[\mathrm{WAr} 2 \cdot \operatorname{Hr}(t)+\mathrm{WAr} 3 \cdot \operatorname{Pa}(t)] \cdot(1-(P c(t))$ \\ $H r(\mathrm{t})=(1-\phi) \cdot N g(\mathrm{t})$}

All of these equilibria conditions can be found in our simulation results. 


\subsection{CONCLUSION}

This article presents the design of a BDI agent model of behavioural change intervention. The model depicts how agent's behavioural factors interact to enhance behaviour change and has been evaluated using mathematical analysis. This model will assist agentbased intervention designers to further understand the mechanism behind agent-based behavioural change intervention. Therefore, it will enable the designers to develop an agent-based intervention system that will be void of reactance.

However, the model does not cover every aspect of human behaviour because human behaviour is as a result of complex interplay of factors that comprise of socio-demographic, cognitive, biological and environmental factors. Further studies that will be done on this model include using Temporal Trace Language (TTL) to evaluate the mode.

Apart from a more thorough evaluation of the proposed models, there are several directions for future research based on the work presented in this article. For example, it is beneficial to investigate how interactions and sensing properties can be further developed and enriched to achieve a more fluid embedding into an intelligent support system.

\section{References}

[1] Bratman, M. E. 1987. Intentions, Plans, and Practical Reason, Harvard University Press: Cambridge, MA

[2] Bisconti, C., A. Corallo, L. Fortunato, and A. A. Gentile. 2014. Quantum-BDI Model for Information Processing and Decision Making. International Journal of Theoretical Physics. 1-17.

[3] Okaya, M., and T. Takahashi. 2011. BDI agent model based evacuation simulation. In The 10th International Conference on Autonomous Agents and Multiagent Systems-Volume 3. International Foundation for Autonomous Agents and Multiagent Systems. 1297-1298.

[4] Casali, A., L. Godo and C. Sierra. 2011. A Graded BDI Agent Model To Represent And Reason About Preferences. Artificial Intelligence. 175(7): 1468-1478.

[5] Rao, A. S., and M. P. Georgeff. 1991. Modeling Rational Agents Within A BDI-Architecture. KR, 91: 473-484.

[6] Bisconti, C., A. Corallo, L. Fortunato, and A. A. Gentile. 2015. A Quantum-BDI Model for Information Processing and Decision Making. International Journal of Theoretical Physics. 54(2): 710-726.

[7] Nunes, I., and M. Luck. 2014. Softgoal-Based Plan Selection In Model-Driven Bdi Agents. In Proceedings of the 2014 International Conference On Autonomous Agents And MultiAgent Systems. International Foundation for Autonomous Agents and Multiagent Systems. 749-756.

[8] Nair, R., and M. Tambe. 2005. Hybrid BDI-POMDP Framework for Multiagent Teaming. J. Artif. Intell. Res.(JAIR). 23: 367-420.

[9] Labrou, Y., T. Finin and Y. Peng. 1999. Agent Communication Languages: The Current Landscape. IEEE Intelligent Systems. 14(2): 45-52

[10] Sutton, S. 2001. Health Behavior: Psychosocial Theories. International Encyclopedia Of The Social And Psychology, retrieved from http://userpage.fuberlin.de/ schuez/folien/Sutton.pdf.

[11] Erdley, C. A., M. S Rivera, and E. J. Shepherd. 2010. Practitioner's Guide to Empirically Based Measures of Social Skills. (D. W. Nangle, D. J. Hansen, C. A. Erdley, \& P. J. Norton, Eds.). 21-36. doi:10.1007/978-1-4419-0609-0.
[12] Conner, M., and P. Norman. 1996. Predicting Health Behaviour: Research And Practice With Social Cognition Models. Open University Press, Buckingham. 1-230.

[13] Sutton, R. S. 1998. Introduction to Reinforcement Learning (Vol. 135). Cambridge: MIT Press

[14] Conner, M, \& P. Norman. 2005. Predicting Health Behaviour: Research And Practice With Social Cognition Models. 2nd ed. Open University Press, Maidenhead. 1-373.

[15] Bandura, A. 1977. Self-efficacy: Toward A Unifying Theory Of Behavioral Change. Psycho-logical Review. 84(2): 191-215.

[16] Bandura, A., and N. E. Adams. 1977. Analysis Of Self-Efficacy Theory Of Behavioral Change. Cognitive Therapy And Research. 1 (4): 287-310.

[17] Pinker, S. 2010. The Cognitive Niche: Coevolution Of Intelligence, Sociality, And Language. Proceedings of the National Academy of Sciences. 107: 8893-8999.

[18] Vohs, K. D., and R. F. Baumeister. 2011. Handbook Of SelfRegulation: Research, Theory, And Applications. Guilford Press.

[19] Fenton-O'Creevy, M., N. Nicholson, and E. Soane. 2003. Trading on Illusions: Unrealistic Perceptions Of Control And Trading Performance. Journal of Occupational and Organisational Psychology. 76: 53-68.

[20] Dubois, D., D. D. Rucker, and R. E. Petty. 2010. Internal versus External Informational Sources: Causes and Consequences for Attitude Certainty and Attitude-Behavior Consistency. Advances in Consumer Research. 37.

[21] Ajzen, I., and M, Fishbein. 1977. Attitude-Behavior Relations: A Theoretical Analysis And Review Of Empirical Research. Psychological Bulletin. 84(5): 888-918. doi:10.1037//00332909.84.5.888.

[22] Hale, J. L. 2002. The Theory Of Reasoned Action. The Persuasion Handbook: Developments In Theory And Practice. 259-286.

[23] Ajzen, I. 2001. Nature And Operation Of Attitudes. Annual Review Of Psychology. Retrieved on December 5, 2012 from http://www.annualreviews.org/doi/pdf/10.1146/annurev.psy ch.52.1.27.

[24] Fishbein, M., and I. Ajzen. 2005. The Influence Of Attitudes On Behaviour. The Handbook Of Attitudes. Retrieved on \begin{tabular}{llll}
\hline December 22, & 2012 & from
\end{tabular} http://www.bm.ust.hk/ mark790b/readings/T5bR2_ajzen200 5.pdf.

[25] Wicker, A. 1969. Attitudes Versus Actions: The Relationship of Verbal And Overt Behavioural Responses To Attitude Objects. Journal Of Social Issues. XXV(4). Retrieved on November $\quad 13, \quad 2012$ from http://onlinelibrary.wiley.com/doi/10.1111/j.1540-

4560.1969.tb00619.x/abstract.

[26] Warehime, R. G. 1972. Generalized Expectancy For Locus Of Control And Academic Performance. Psychological Reports. 30: 314.

[27] Montano, D. E., and D. Kasprzyk. 2008. Theory Of Reasoned Action, Theory Of Planned Behaviour, And The Integrated Behavioral Model. Health Behaviour And Health Education: Theory, Research, And Practice. 4: 67-95

[28] Henshaw, E. J., and C. R. Freedman-Doan. 2009 Conceptualizing Mental Health Care Utilization Using The Health Belief Model. Clinical Psychology: Science and Practice. 16(4): 420-439.

[29] Fogg, B. J. 2009. A Behaviour Model For Persuasive Design. Proceedings of the 4th International Conference on Persuasive Technology. 1. doi:10.1145/1541948.1541999.

[30] Young, M. M. 2010. Twitter Me: Using Micro-Blogging To Motivate Teenagers To Exercise. In Global Perspectives on Design Science Research. Springer Berlin Heidelberg. 439448.

[31] Linehan, C., M. Doughty, and S. Lawson. 2010. Tagliatelle: Social Tagging To Encourage Healthier Eating. CHI' 10 Extended, 3331-3336. Retrieved from http://dl.acm.org/Citation.cfm?id=1753980. 
[32] Layne, K., and J. Lee. 2001. Developing Fully Functional EGovernment: A Four Stage Model. Government Information Quarterly. 18(2): 122-136.

[33] Larimer, M., and R. Palmer. 1999. Relapse Prevention: An Overview Of Marlatt's Cognitive-Behavioral Model. Alcohol Research And Health. 23(2): 151-160. Retrieved on November 12 , $2012 \quad$ from http://94.23.146.173/ficheros/5f61d4b2c6982926b32d44c880 9566f0.pdf.

[34] Hendershot, C. S., K. Witkiewitz, W. H. George, and G. A. Marlatt. 2011. Relapse Prevention For Addictive Behaviors. Substance Abuse Treatment, Prevention, And Policy. 6(1): 17.

[35] Katz, J. L., and S. T. Higgins. 2003. The Validity Of The Reinstatement Model Of Craving And Relapse To Drug Use. Psychopharmacology (Berl.). $\quad$ 168(1-2): 21-30. doi:10.1007/s00213-003-1441-y. PMID 12695875.

[36] Prochaska, J. O., S. Butterworth, C. A. Redding, V. Burden, N. Perrin, M. Leo, M. Flaherty-Robb, and J. M. Prochaska. 2009. Initial Efficacy Of MI, TTM Tailoring And HRI's With Multiple Behaviors For Employee Health Promotion. 46(3): 226-31.

[37] Tierney, D. W., and M. P. McCabe. 2001. The Validity Of The Trans-Theoretical Model Of Behaviour Change To Investigate
Motivation To Change Among Child Molesters. Clinical Psychology \& Psychotherapy. 8(3): 176-190.

[38] Klein, M., N. Mogles, and A. Van. Wissen. 2011. Why Won't You Do What's Good For You? Using Intelligent Support For Behaviour Change. Human Behaviour Understanding. 104115. Retrieved on December 28, 2012 from http://www.springerlink.com/index/T17K156375587701.pdf.

[39] West, R. 2009. How Can We Better Understand Human Motivation? Thorax. 55: 987-999.

[40] Nunes, I., and M. Luck. 2014. Softgoal-based Plan Selection In Model-Driven Bdi Agents. In Proceedings of the 2014 International Conference On Autonomous Agents And MultiAgent Systems. International Foundation for Autonomous Agents and Multiagent Systems. 749-756.

[41] Vidotto, G., and M. Vicentini. 2007. A General Method For Parameter Estimation Of Averaging Models. Teorie \& Modelli. 12(1-2): 211-221

[42] Wang, Y., K. M. Kockelman, and X. C. Wang. 2013. The Impact Of Weight Matrices On Parameter Estimation And Inference: A Case Study Of Binary Response Using Land-Use Data. Journal of Transport and Land Use. 6(3): 75-85. 